\title{
Collateral vessels on magnetic resonance angiography in endovascular-treated acute ischemic stroke patients associated with clinical outcomes
}

\author{
Liang Jiang ${ }^{1, *}$, Hao-Bo Su ${ }^{2, *}$, Ying-Dong Zhang ${ }^{3}$, Jun-Shan Zhou ${ }^{3}$, Wen Geng ${ }^{1}$, \\ Huiyou Chen ${ }^{1}$, Quan $X u^{1}$, Xindao Yin $^{1}$ and $Y u-C h e n C^{1}$ \\ ${ }^{1}$ Department of Radiology, Nanjing First Hospital, Nanjing Medical University, Nanjing, China \\ ${ }^{2}$ Department of Vascular and Interventional Radiology, Nanjing First Hospital, Nanjing Medical University, Nanjing, China \\ ${ }^{3}$ Department of Neurology, Nanjing First Hospital, Nanjing Medical University, Nanjing, China \\ *These authors contributed equally to this work
}

Correspondence to: Yu-Chen Chen, email: chenyuchen1989@126.com Xindao Yin, email: y.163yy@163.com

Keywords: acute ischemic stroke, collateral vessels, endovascular recanalization, MRI

Received: August 09, $2017 \quad$ Accepted: September 03, $2017 \quad$ Published: September 19, 2017

Copyright: Jiang et al. This is an open-access article distributed under the terms of the Creative Commons Attribution License 3.0 (CC BY 3.0), which permits unrestricted use, distribution, and reproduction in any medium, provided the original author and source are credited.

\section{ABSTRACT}

Purpose: Collateral vessels were considered to be related with outcome in endovascular-treated acute ischemic stroke patients. This study aimed to evaluate whether the collateral vessels on magnetic resonance angiography (MRA) could predict the clinical outcome.

Materials and Methods: Acute stroke patients with internal carotid artery or middle cerebral artery occlusion within 6 hours of symptom onset were included. All patients underwent MRI and received endovascular treatment. The collateral circulations at the Sylvian fissure and the leptomeningeal convexity were evaluated. The preoperative and postoperative infarct volume was measured. The clinical outcome was evaluated by $\mathrm{mRS}$ score at 3 months after stroke.

Results: Of 55 patients, Cases with insufficient collateral circulation at the Sylvian fissure and leptomeningeal convexity showed that the NIHSS score at arrival and preoperative infarct volume were significantly lower in $\mathrm{mRS}$ score of $0-2$ (both $P<0.05$ ) than $\mathrm{mRS}$ score of 3-6. Multivariate testing revealed age and collateral status at the leptomeningeal convexity were independent of the clinical outcome at 3 months after stroke (odds ratio (95\% confidence interval): 1.094 (1.025-1.168); $9.542(1.812-50.245)$ respectively). The change of infarct volume in the group with mRS score of 0-2 was smaller than that with mRS score of 3-6. While multivariate logistic models showed that postoperative infarct volume was non-significant in predicting the clinical outcome after stroke.

Conclusions: The extent of collateral circulation at the leptomeningeal convexity may be useful for predicting the functional recovery while the relationship between postoperative infarct volume and clinical outcome still requires for further study.

\section{INTRODUCTION}

Acute ischemic stroke (AIS) is the most common type of stroke, accounting for about $80 \%$ of the total cerebral apoplexy [1]. It is the third leading cause of death worldwide. In recent years, the incidence of AIS is increasing and often leads to devastating motor disability [2-4], especially the AIS caused by the middle cerebral artery occlusion. As a new method for treatment of AIS, endovascular recanalization can increase the recanalization of occluded cerebral arteries quickly and significantly [5-9]. The latest clinical practice guideline recommends an endovascular recanalization strategy for AIS if the intervention can be applied within 6 hours from 
last seen normal [10]. AIS outcome varies considerably due to the compensatory ability of the collateral circulation and the ensuing cerebral blood flow $[11,12]$. Good angiographic collaterals have been associated with improved recanalization [13].

Multi-parametric magnetic resonance imaging (MRI), including diffusion-weighted imaging (DWI), perfusion-weighted imaging (PWI), and magnetic resonance angiography (MRA), has increasingly been used to optimize the therapy strategy after stroke $[14,15]$. As a noninvasive imaging method, MRI has also become a recent trend to visualize collaterals [16]. The primary collateral circulation is occasionally established via leptomeningeal anastomoses from the anterior cerebral artery and posterior cerebral artery (PCA) when the proximal middle cerebral arteries (MCA) occlusion. Prominent PCA laterality on three-dimensional time-of-flight (3D-TOF) MRA was reported as a MRI radiologic marker of collateral flow $[17,18]$. Good collateral circulation could independently predict good outcome in AIS [19, 20]. Poor arterial collateralization was associated with poor outcome after recanalization success [21]. A favorable arterial collateralization as determined by leptomeningeal anastomoses may improve post-revascularization outcome $[12,13]$.

Previous experimental studies showed that symptom onset to recanalization, initial stroke severity at presentation in the form of the National Institutes of Health Stroke Scale (NIHSS) or infarct volume on imaging play a role in influencing ultimate clinical outcome $[22,23]$. In this study, we focused on the association between the baseline collateral status on MRA and stroke outcomes after endovascular recanalization. In addition to investigate the effects of the infarct volume on the initial collateral flow and the final functional status, we also compared the collateral circulation, infarct volume between pre and post treatment.

\section{MATERIALS AND METHODS}

\section{Patient selection and evaluation}

This was an observational and prospective study. Our analysis was performed on data collected from a prospective registry of patients who were eligible for recanalization therapy for acute infarct of MCA and/or internal carotid artery (ICA). The stroke patients who admitted to Nanjing First Hospital between October 2015 and March 2017 were analyzed. The inclusion criteria for this study were: (1) ischemic stroke with relevant infarction that was documented by relevant neuroimaging studies, (2) presentation within 6 hours of symptom onset and receive endovascular recanalization treatment, (3) severe stenosis or occlusion in the ICA or proximal MCA including the main stem (M1) or secondary trunks (M2). The following exclusion criteria were also applied: (1) missing modified Rankin Scale (mRS) score at 3 months after stroke, (2) no non-contrast CT and MRI examination before the endovascular recanalization therapy, or the MRI which has motion artifact was unable to evaluate. (3) hemodynamically irrelevant stenosis or a bilateral steno-occlusion that prevented measurement of the collateral status, (4) no endovascular recanalization treatment. Finally a total of 55 cases are eligible for the current analysis according to the inclusion and exclusion criteria. Acute stroke management was performed according to the current clinical practice guidelines for stroke care, institutional protocols, and at the discretion of individual physicians with direct liability [24, 25]. The local Institutional Review Board approved this study and all patients gave their consent to participate in the study.

We evaluated all study participants according to a protocol that included baseline demographic and clinical information, including age, sex, history of previous stroke, hypertension, diabetes mellitus, hyperlipidemia, atrial fibrillation, habitual smoking, the NIHSS on admission, and mRS score at 3 months after the onset of symptoms. Good clinical outcome was defined as a mRS score $\leq 2$ at 3 months [26].

\section{CT, MRI methods and image analysis}

Non-enhanced CT image was acquired according to standard departmental protocols with a 16-channel multidetector CT scanner (Sensation 16, Siemens, Germany). Non-enhanced CT was performed with the patient in head holder in the transverse plane with minimal variations between scanners, and with scanning parameters of $120 \mathrm{kVP}, 250 \mathrm{mAS}$, and 5-mm section thickness. MRI was performed using a 3.0 T unit (Ingenia; Philips Medical Systems, Netherlands). The MRI protocol included the fluid-attenuated inversion recovery (FLAIR), DWI and 3D-TOF MRA. FLAIR MRI parameters were obtained axially using inverse recovery (IR) sequence as follows: repetition time (TR), $7000 \mathrm{~ms}$; echo time (TE), $120 \mathrm{~ms}$; acquisition matrix, 356*151; field of view (FOV), 230 $\mathrm{mm} * 230 \mathrm{~mm}$;flip angle (FA), $90^{\circ} \mathrm{C}$; slices, 18 ; section thickness, $6 \mathrm{~mm}$; and intersection gap, $1.3 \mathrm{~mm}$. DWI was performed using spin echo (SE) sequence, the following parameters: TR, $2501 \mathrm{~ms}$; TE, $98 \mathrm{~ms}$; acquisition matrix, $152 * 122$; 3 directions; FOV, $230 \mathrm{~mm} * 230 \mathrm{~mm}$; FA, $90^{\circ} \mathrm{C}$; slices, 18 ; section thickness, $6 \mathrm{~mm}$; and intersection gap, $1.3 \mathrm{~mm}$. DWI was obtained with $\mathrm{b}$ values of 0 and $1000 \mathrm{~s} / \mathrm{mm}^{2}$. 3D-TOF MRA were obtained using fast field echo (FFE) sequence, parameters were as follows: TR, $22 \mathrm{~ms}$; TE, $3.5 \mathrm{~ms}$; acquisition matrix, 400*232; FOV, $240 \mathrm{~mm} * 240 \mathrm{~mm}$; FA, $18^{\circ} \mathrm{C}$; slices, 140 ; section thickness, $20 \mathrm{~mm}$; and intersection gap, $10 \mathrm{~mm}$.

Collateral status was measured primarily using a method proposed by Maas et al. [27]. The collateral vessels in the Sylvian fissure and leptomeningeal convexity were assessed in the contrast-enhanced MRA images of 2-mm section separately. The collateral vessels of the occluded hemisphere mainly compared with the 
patent hemisphere, as follows: 1 , absent; 2 , less than the patent contralateral side; 3 equal to the patent contralateral side; 4 greater than the patent contralateral side; and 5, exuberant. The collateral status was separately categorized into insufficient (grade $\leq 2$ ) and sufficient (grade $\geq 3$ ). Hyperintense vessels (HV) were defined as a linear or curved hyperintensity on FLAIR MRI corresponding to a typical arterial course. Ten imaging slices, from the first M1 MCA appearance rostrocaudally to the tenth image, were analyzed and one or more HVs recognized on one slice were rated one point. The resulting $\mathrm{HV}$ score ranged from 0 to 10 . Two neuroradiologists (H-B S and $\mathrm{XY}$ ) assessed the collateral status and HV. In case of a discrepant score between the two readers, images were reviewed and a consensus was established.

DWI lesion volume measurements were performed by the author who was blinded to the clinical information. DWI lesion volume was measured semiautomatically using Philips workstation (IntelliSpace Portal). Two reviewers who were blinded to the study purpose and clinical characteristics assessed the reperfusion status using the modified Thrombolysis in Cerebral Infarction (TICI) score in postrecanalization conventional angiography images [28].

\section{Statistical analyses}

Continuous data are shown as the mean $\pm \mathrm{SD}$, whereas categorical variables are presented as absolute and relative frequencies. We analyzed differences between groups using chi-squared test for categorical variables and the independent-samples $t$-test or Fisher's exact test for continuous variables. In addition, multivariate logistic regression analysis was performed to predict the independent contribution of factors in clinical outcome. $P<0.05$ was considered statistically significant. All statistical analyses were conducted using commercially available software (SPSS for Windows, version 19.0; SPSS).

\section{RESULTS}

A total of 55 patients were included in this study: 33 men and 22 women with a mean age of $68.96 \pm 13.54$ years (range, 32-89 years). The median NIHSS score at arrival was $12.71 \pm 5.14$. On the contrast enhanced MRA images, the collateral circulation was sufficient in $3(5.45 \%)$ and $10(18.18 \%)$ cases involving the Sylvian fissure and leptomeningeal convexity collateral vessels respectively. The infarct volume on onset MRI was 43.98 $\pm 78.13 \mathrm{ml}$, with a median HV score of $5.09 \pm 2.20$ points. After endovascular recanalization treatment, successful recanalization to a modified TICI score of $\geq 2 \mathrm{~b}$ was achieved in $46(83.64 \%)$ cases; The mRS score was $0-2$ at 3 months after stroke in $18(32.73 \%)$ cases, but $4(7.27 \%)$ cases had died in 3 months (Table 1).

The baseline clinical characteristics and infarct volume onset of the insufficient collateral circulation at the
Sylvian fissure and leptomeningeal convexity according to favorable functional recovery at 3 months after stroke are presented in Table 2. Both of insufficient collateral circulation at the Sylvian fissure and leptomeningeal convexity, the NIHSS score at arrival and preoperative infarct volume on onset MRI were significantly lower in mRS score of $0-2$ (both $P<0.05$ ). After conventional angiography, successful recanalization (modified TICI score of $\geq 2 b$ ) was more frequently observed in the group with mRS score of $0-2$, but the differences did not reach statistical significance (at the Sylvian fissure: $P=0.102$; at the leptomeningeal convexity: $P=0.187)$. Multivariate logistic models showed that age and collateral status at the leptomeningeal convexity were independently affected the functional recovery at 3 months after stroke, while the NIHSS score and infarct volume onset were not significant in predicting the functional recovery after stroke (Table 3 ).

The postoperative infarct volume was slightly larger than that of pre-operation in group with mRS score of 0-2, while in group with mRS score 3-6, the postoperative infarct volume became larger obviously, both groups were statistically different $(P=0.039 ; P=0.002)$. The $\mathrm{HV}$ almost disappeared after operation, especially in the group with $\mathrm{mRS}$ score of $0-2(P<0.001 ; P<0.001)$. The postoperative collateral circulation at the Sylvian fissure and leptomeningeal convexity was much better than that in pre-operation (Table 4, Figures 1 and 2). While multivariate logistic models showed that postoperative infarct volume, HV, collateral status at the Sylvian fissure and at the leptomeningeal convexity were not significant in predicting the functional recovery after stroke (Table 5).

\section{DISCUSSION}

From our analysis of 55 AIS patients who were treated with an endovascular recanalization procedure, we found that most of collateral circulation was insufficient, $94.55 \%$ and $81.82 \%$ of collateral status at the Sylvian fissure and the leptomeningeal convexity respectively. In the patients with insufficient collateral circulation, age, NIHSS score at arrival and infarct volume onset were significant different between mRS score of 0-2 and mRS score of 3-6. The age and collateral status at the leptomeningeal convexity was the predictor for the functional recovery at 3 months after stroke. After operation, the infarct volume became larger, the HV almost disappeared and a majority of the collateral circulation was sufficient.

The collateral circulation seems functionally inactive in the normal and stable brain, after focal cerebral ischemia, cerebral arteries and capillaries in the brain are impaired early [29, 30], collateral blood supply to vessels and brain tissue located within the territory of the occluded artery to minimize the degree of ischemic vascular. Since early collateral development via leptomeningeal anastomoses after MCA occlusion is induced by a 
Table 1: Demographic and clinical characteristics, image findings of all patients $(n=55)$

\begin{tabular}{|c|c|}
\hline Variables & Value \\
\hline Male sex $(\%)$ & $33(60)$ \\
\hline Age (years) & $68.96 \pm 13.54$ \\
\hline Hypertension (\%) & $44(80)$ \\
\hline Diabetes $(\%)$ & $7(12.73)$ \\
\hline Dyslipidemia (\%) & $27(49.09)$ \\
\hline Habitual smoker (\%) & $7(12.73)$ \\
\hline Atrial fibrillation (\%) & $30(54.55)$ \\
\hline NIHSS score at arrival & $12.71 \pm 5.14$ \\
\hline Onset-to-CT-imaging time (minutes) & $102.71 \pm 54.01$ \\
\hline Onset-to-MRI-imaging time (minutes) & $182.31 \pm 58.49$ \\
\hline Onset-to-DSA-imaging time (minutes) & $244.07 \pm 70.54$ \\
\hline Onset-to-reperfusion time (minutes) & $323.91 \pm 81.68$ \\
\hline \multicolumn{2}{|l|}{ Location of symptomatic occlusion (\%) } \\
\hline Middle cerebral artery-M1 & $25(45.45)$ \\
\hline Middle cerebral artery-M2 & $7(12.73)$ \\
\hline Intracranial internal cerebral artery & $7(12.73)$ \\
\hline Extracranial internal cerebral artery & $10(18.18)$ \\
\hline Both middle cerebral artery and internal cerebral artery & $6(10.91)$ \\
\hline \multicolumn{2}{|l|}{ Collateral status at the Sylvian fissure (\%) } \\
\hline Insufficient & $52(94.55)$ \\
\hline Sufficient* & $3(5.45)$ \\
\hline \multicolumn{2}{|l|}{ Collateral status at the leptomeningeal convexity (\%) } \\
\hline Insufficient & $45(81.82)$ \\
\hline Sufficient ${ }^{*}$ & $10(18.18)$ \\
\hline \multicolumn{2}{|l|}{ Recanalization treatment (\%) } \\
\hline Endovascular recanalization only & $20(36.36)$ \\
\hline Combined intravenous and endovascular recanalization & $35(63.64)$ \\
\hline Infarct volume on onset MRI (mL) & $43.98 \pm 78.13$ \\
\hline $\mathrm{HV}$ & $5.09 \pm 2.20$ \\
\hline Successful recanalization (modified TICI score of $\geq 2 b$ ) (\%) & $46(83.64)$ \\
\hline mRS score of 0-2 at 3 months after stroke (\%) & $18(32.73)$ \\
\hline Mortality rate at 3 months after stroke (\%) & $4(7.27)$ \\
\hline
\end{tabular}

Data are mean $\pm \mathrm{SD}, \mathrm{n}(\%)$, or median (interquartile range) values.

*A sufficient collateral circulation indicates the collaterals in the ischemic hemisphere $\geq 3$ points. NIHSS, National Institutes of Health Stroke Scale, TICI, Thrombolysis in Cerebral Infarction, mRS, modified Rankin Scale. HV, hyperintense vessels.

pressure gradient between the anterior cerebral artery or PCA territory and a territory distal to the MCA occlusion site [30], these collateral circulation may protect brain tissue and/or vessel structures from ischemic damage until MCA recanalization. Our study suggested that there existed association between collateral circulation and good outcome. Patients with sufficient collateral status at the leptomeningeal convexity showed a trend for better outcomes, odds ratio $9.542(1.812-50.245)$. The smaller odds ratio in our study could imply that patients with good collaterals are more favorable, while the collateral status at the Sylvian fissure is not significant association with good outcome. Leptomeningeal collaterals have been considered as a beneficial role in AIS patients [16]. The leptomeningeal collateral circulation can preserve cerebral blood flow in the territory of the occluded artery [30], and well-developed leptomeningeal collateral circulation can maintain the perfusion of penumbral regions and protect 
Table 2: Results of bivariate analyses according to functional recovery at 3 months after stroke among subjects with an insufficient collateral circulation

\begin{tabular}{|c|c|c|c|c|c|c|}
\hline \multirow{2}{*}{ Variable } & \multicolumn{3}{|c|}{$\begin{array}{l}\text { Insufficient collateral status } \\
\text { at the Sylvian fissure }(n=52)\end{array}$} & \multicolumn{3}{|c|}{$\begin{array}{l}\text { Insufficient collateral status } \\
\text { at the leptomeningeal convexity }(n=45)\end{array}$} \\
\hline & $\begin{array}{c}\text { mRS score of } \\
0-2(n=16)\end{array}$ & $\begin{array}{c}\text { mRS score of } \\
3-6(n=36)\end{array}$ & $\boldsymbol{P}$ & $\begin{array}{c}\text { mRS score of } \\
0-2(n=11)\end{array}$ & $\begin{array}{c}\text { mRS score of } \\
3-6(n=34)\end{array}$ & $P$ \\
\hline Male sex $(\%)$ & $12(75)$ & $20(55.56)$ & 0.183 & $7(63.64)$ & $19(55.88)$ & 0.919 \\
\hline Age (years) & $64.00 \pm 11.92$ & $72.89 \pm 10.98$ & 0.011 & $65.36 \pm 11.88$ & $72.12 \pm 10.80$ & 0.085 \\
\hline Hypertension (\%) & $12(75)$ & $31(86.11)$ & 0.562 & $8(72.73)$ & $30(88.24)$ & 0.450 \\
\hline Diabetes (\%) & $3(18.75)$ & $3(8.33)$ & 0.539 & $3(27.27)$ & $3(8.82)$ & 0.192 \\
\hline Dyslipidemia (\%) & $5(31.25)$ & $20(55.56)$ & 0.105 & $3(27.27)$ & $20(58.82)$ & 0.069 \\
\hline Habitual smoker (\%) & $0(0)$ & $7(19.44)$ & 0.145 & $0(0)$ & $6(17.65)$ & 0.324 \\
\hline Atrial fibrillation (\%) & $6(37.5)$ & $22(61.11)$ & 0.115 & $4(36.36)$ & $20(58.82)$ & 0.194 \\
\hline NIHSS score at arrival & $10.06 \pm 4.65$ & $14.25 \pm 4.91$ & 0.006 & $10.36 \pm 5.45$ & $14.41 \pm 4.99$ & 0.027 \\
\hline Onset-to-CT-imaging time (minutes) & $88.88 \pm 43.02$ & $105.69 \pm 59.05$ & 0.311 & $91.09 \pm 46.68$ & $103.79 \pm 58.71$ & 0.518 \\
\hline Onset-to-MRI-imaging time (minutes) & $167.69 \pm 52.04$ & $187.19 \pm 61.53$ & 0.275 & $180.18 \pm 50.36$ & $186.35 \pm 62.08$ & 0.767 \\
\hline Onset-to-DSA-imaging time (minutes) & $228.56 \pm 64.35$ & $247.47 \pm 74.60$ & 0.384 & $236.55 \pm 67.31$ & $245.59 \pm 76.22$ & 0.727 \\
\hline Onset-to-reperfusion time (minutes) & $296.44 \pm 82.82$ & $337.00 \pm 81.77$ & 0.106 & $303.27 \pm 87.36$ & $338.50 \pm 83.51$ & 0.236 \\
\hline Location of symptomatic occlusion (\%) & & & 0.006 & & & 0.020 \\
\hline Middle cerebral artery-M1 & $7(43.75)$ & $18(50)$ & & $4(36.36)$ & $17(50)$ & \\
\hline Middle cerebral artery-M2 & $0(0)$ & $6(16.67)$ & & $0(0)$ & $5(14.71)$ & \\
\hline Intracranial internal cerebral artery & $4(25)$ & $2(5.56)$ & & $2(18.18)$ & $2(5.88)$ & \\
\hline Extracranial internal cerebral artery & $5(31.25)$ & $4(11.11)$ & & $5(45.45)$ & $4(11.76)$ & \\
\hline Both middle cerebral artery and internal cerebral artery & $0(0)$ & $6(16.67)$ & & $0(0)$ & $6(17.65)$ & \\
\hline Recanalization treatment $(\%)$ & & & 0.429 & & & 1 \\
\hline Endovascular recanalization only & $6(37.5)$ & $13(36.11)$ & & $4(36.36)$ & $12(35.29)$ & \\
\hline Combined intravenous and endovascular recanalization & $10(62.5)$ & $13(36.11)$ & & $7(63.64)$ & $22(64.71)$ & \\
\hline Infarct volume on onset MRI (mL) & $13.61 \pm 10.99$ & $59.80 \pm 92.74$ & 0.006 & $11.62 \pm 8.58$ & $62.84 \pm 94.61$ & 0.004 \\
\hline HV & $5.19 \pm 2.64$ & $5.14 \pm 1.91$ & 0.941 & $6.00 \pm 2.14$ & $5.06 \pm 1.94$ & 0.179 \\
\hline Successful recanalization (modified TICI score of $\geq 2 b$ ) (\%) & $16(100)$ & $28(77.78)$ & 0.102 & $11(100)$ & $26(76.47)$ & 0.187 \\
\hline
\end{tabular}

HV, Hyperintense vessels, TICI, Thrombolysis in Cerebral Infarction, mRS, modified Rankin Scale.

Table 3: Multivariate analysis of the preoperative predictors of functional recovery at 3 months after stroke $(n=55)$

\begin{tabular}{lcc}
\hline Multivariable variable & $\begin{array}{c}\text { Odds ratio } \\
\text { (95\% confidence interval) }\end{array}$ & $\boldsymbol{P}$ \\
\hline Mode 1: age, NIHSS score & $1.079(1.025-1.136)$ & 0.004 \\
Age & & \\
Model 2: model1 + preoperative infarct volume & $1.088(1.027-1.154)$ & 0.004 \\
Age & $1.033(0.988-1.080)$ & 0.154 \\
Preoperative infarct volume & & 0.007 \\
Model 3: model2 + collateral status & $1.094(1.025-1.168)$ & 0.008 \\
Age & $9.542(1.812-50.245)$ & \\
Collateral status at the leptomeningeal convexity &
\end{tabular}

NIHSS, National Institutes of Health Stroke Scale.

distal brain tissues [31, 32]. The prior studies showed that the collateral circulation can predict outcome irrespective of final recanalization status $[19,33,34]$, which was consistent with our study that considered sufficient collateral status at the leptomeningeal convexity as a predictor for good clinical outcome. 
Table 4: Comparison of facts between pre-operation and post-operation

\begin{tabular}{lcccccc}
\hline \multirow{2}{*}{ Variable } & \multicolumn{2}{c}{ mRS score of 0-2 $(\boldsymbol{n}=\mathbf{1 1})$} & \multicolumn{3}{c}{ mRS score of 3-6 $(\boldsymbol{n}=\mathbf{2 3})$} \\
\cline { 2 - 6 } & Pre-operation & Post-operation & $\boldsymbol{P}$ & Pre-operation & Post-operation & $\boldsymbol{P}$ \\
\hline Infarct volume on MRI $(\mathrm{mL})$ & $14.15 \pm 10.73$ & $21.39 \pm 17.41$ & 0.039 & $16.88 \pm 16.64$ & $57.27 \pm 56.67$ & 0.002 \\
HV & $5.00 \pm 2.90$ & $0.36 \pm 0.81$ & 0.000 & $5.22 \pm 1.76$ & $1.74 \pm 2.68$ & 0.000 \\
Collateral status at the Sylvian fissure & $1.91 \pm 0.70$ & $3.00 \pm 0.00$ & 0.000 & $1.83 \pm 0.49$ & $2.70 \pm 0.47$ & 0.000 \\
Collateral status at the leptomeningeal convexity & $2.45 \pm 1.21$ & $3.09 \pm 0.30$ & 0.089 & $1.52 \pm 0.73$ & $2.48 \pm 0.95$ & 0.000 \\
\hline
\end{tabular}

HV: Hyperintense vessels, mRS: modified Rankin Scale.

Another important finding of this study is that the postoperative infarct volume was slightly larger than that of pre-operation in group with $\mathrm{mRS}$ score of $0-2$, while in group with mRS score $3-6$, the postoperative infarct volume became larger obviously. Both groups with $\mathrm{mRS}$ score of $0-2$ and of 3-6 were statistically different. Son et al. showed that the degree of infarct growth differed depending on the collateral status, regardless of successful recanalization [35]. In our study, the collateral circulation at the Sylvian fissure and leptomeningeal convexity was much better in post-operation, especially in the group with mRS score of $0-2$. The results demonstrate that most patients have HV in the insufficient collateral circulation. However, when the collateral circulation is sufficient, the HV almost disappear. These results may be explained by the speed of collateral flow. Distal HV are thought to be linked with stationary blood and slow antegrade collateral or retrograde collateral circulation [36, 37]. Kim

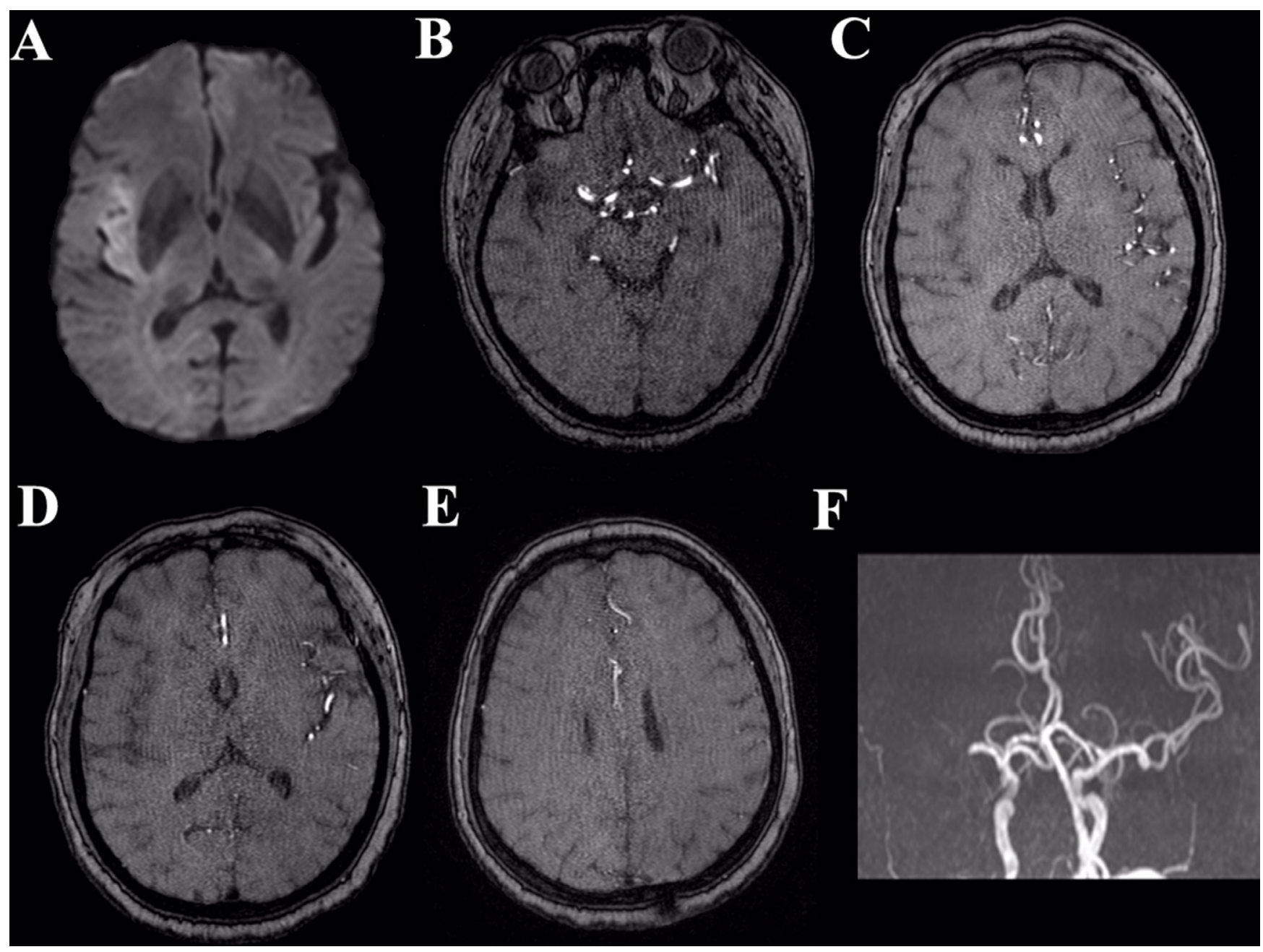

Figure 1: Illustrative case depicting the collateral status from preoperative MRI. Preoperative DWI (A) shows acute cerebral infarction in the right temporal lobe. Sylvian collateral $(\mathbf{B}, \mathbf{C})$ poor. Leptomeningeal collateral $(\mathbf{D}, \mathbf{E})$ : poor. 3D-TOF MRA (F) shows occlusion of right MCA. 
Table 5: Multivariate analysis of the postoperative predictors of functional recovery at 3 months after stroke $(n=34)$

\begin{tabular}{lcc}
\hline Multivariable variable & $\begin{array}{c}\text { Odds ratio } \\
(\mathbf{9 5 \%} \text { confidence interval) }\end{array}$ & $\boldsymbol{P}$ \\
\hline postoperative infarct volume & $1.027(0.990-1.066)$ & 0.154 \\
HV & $0.735(0.279-1.939)$ & 0.534 \\
Collateral status at the Sylvian fissure & 0.000 & 0.999 \\
Collateral status at the leptomeningeal convexity & $0.512(0.026-9.996)$ & 0.658 \\
\hline
\end{tabular}

HV, Hyperintense vessels.

et al. thought that if patients with MCA occlusion have sufficiently rapid collaterals from arteries unaffected by occlusion, distal HV beyond the site of arties occlusion may not be identified on FLAIR images [26]. Based on our results, postoperative infarct volume and $\mathrm{HV}$ cannot be used to predict the functional recovery.

Several limitations should be noted in the current study. Firstly, this is a retrospective case-control study with a limited sample size that might cause overestimation.
More samples were still required to establish the influence of collateral circulation on clinical outcome. Secondly, although the site of occlusion may be associated with the collateral status, we did not analyze it further mainly due to small number of subjects. Moreover, the post-operative infarct volume was measured within 24 hours after operation, it will be better for evaluating the infarct volume change in 7 days and/or one month due to the infarct volume stationary relatively without ischemic penumbra influence.
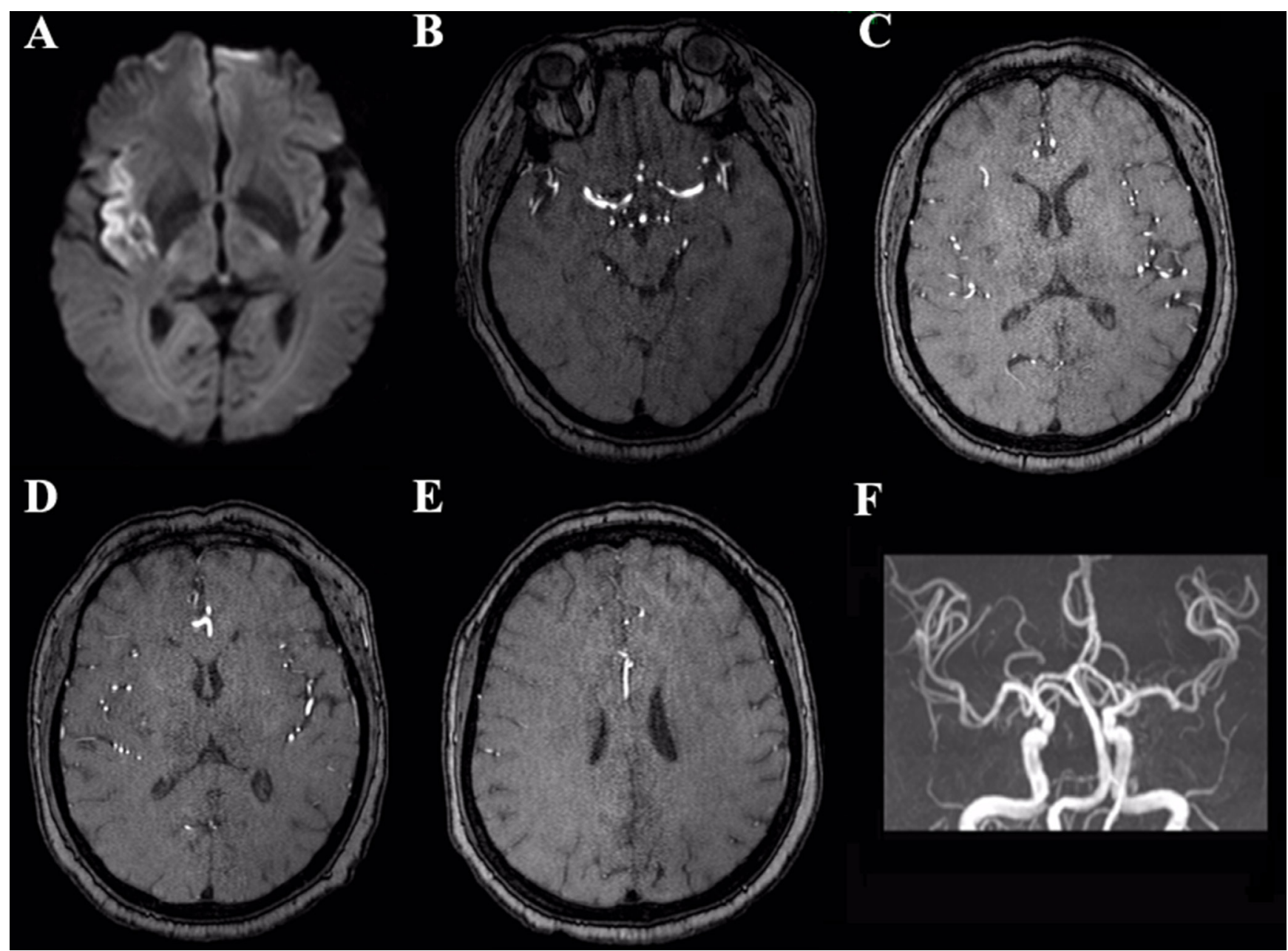

Figure 2: The same case with postoperative MRI imagings (A-F). Postoperative DWI (A) demonstrates the lesion mid enlargement. Sylvian collateral (B, C) adequate. Leptomeningeal collateral (D, E) adequate. 3D-TOF MRA (F) shows right MCA normal. 


\section{CONCLUSIONS}

In summary, a sufficient baseline collateral status in acute ischemic stroke patients was associated with improved functional recovery and decreased mortality rate at 3 months after stroke. In addition, the age and collateral status at the leptomeningeal convexity may be useful markers for the prediction of functional recovery.

\section{ACKNOWLEDGMENTS AND FUNDING}

This work was funded by Jiangsu Provincial Special Program of Medical Science (BE2017614), Youth Medical Talents of Jiangsu Province (No. QNRC2016062), and China Postdoctoral Science Foundation (No. 2017M610337). LJ and H-B S designed the experiment, collected the data, performed the analysis, and wrote the paper. J-S Z, WG, HC and QX helped collect the data and perform the analysis. Y-D Z, XY and Y-C C contributed to the discussion and manuscript revision.

\section{CONFLICTS OF INTERESTS}

The authors declare that there is no potential conflict of interests regarding the publication of this paper.

\section{REFERENCES}

1. Eswaradass PV, Swartz RH, Rosen J, Hill MD, Lindsay MP. Access to hyperacute stroke services across Canadian provinces: a geospatial analysis. CMAJ Open. 2017; 5:E454-E9.

2. Anuncibay-Soto B, Santos-Galdiano M, FernandezLopez A. Neuroprotection by salubrinal treatment in global cerebral ischemia. Neural Regen Res. 2016; 11:1744-5.

3. Feigin VL, Forouzanfar MH, Krishnamurthi R, Mensah GA, Connor M, Bennett DA, Moran AE, Sacco RL, Anderson L, Truelsen T, O’Donnell M, Venketasubramanian N, BarkerCollo S, et al. Global and regional burden of stroke during 1990-2010: findings from the Global Burden of Disease Study 2010. Lancet. 2014; 383:245-54.

4. Crichton SL, Bray BD, McKevitt C, Rudd AG, Wolfe CD. Patient outcomes up to 15 years after stroke: survival, disability, quality of life, cognition and mental health. J Neurol Neurosurg Psychiatry. 2016; 87:1091-8.

5. Berkhemer OA, Fransen PS, Beumer D, van den Berg LA, Lingsma HF, Yoo AJ, Schonewille WJ, Vos JA, Nederkoorn PJ, Wermer MJ, van Walderveen MA, Staals J, Hofmeijer $\mathrm{J}$, et al. A randomized trial of intraarterial treatment for acute ischemic stroke. N Engl J Med. 2015; 372:11-20.

6. Goyal M, Demchuk AM, Menon BK, Eesa M, Rempel JL, Thornton J, Roy D, Jovin TG, Willinsky RA, Sapkota BL, Dowlatshahi D, Frei DF, Kamal NR, et al. Randomized assessment of rapid endovascular treatment of ischemic stroke. N Engl J Med. 2015; 372:1019-30.
7. Campbell BC, Mitchell PJ, Kleinig TJ, Dewey HM, Churilov L, Yassi N, Yan B, Dowling RJ, Parsons MW, Oxley TJ, Wu TY, Brooks M, Simpson MA, et al. Endovascular therapy for ischemic stroke with perfusionimaging selection. N Engl J Med. 2015; 372:1009-18.

8. Jovin TG, Chamorro A, Cobo E, de Miquel MA, Molina CA, Rovira A, San Roman L, Serena J, Abilleira S, Ribo M, Millan M, Urra X, Cardona P, et al. Thrombectomy within 8 hours after symptom onset in ischemic stroke. N Engl J Med. 2015; 372:2296-306.

9. Casaubon LK, Boulanger JM, Blacquiere D, Boucher S, Brown K, Goddard T, Gordon J, Horton M, Lalonde J, LaRiviere C, Lavoie P, Leslie P, McNeill J, et al. Canadian Stroke Best Practice Recommendations: Hyperacute Stroke Care Guidelines, Update 2015. Int J Stroke. 2015; 10:924-40.

10. Powers WJ, Derdeyn CP, Biller J, Coffey CS, Hoh BL, Jauch EC, Johnston KC, Johnston SC, Khalessi AA, Kidwell CS, Meschia JF, Ovbiagele B, Yavagal DR, et al. 2015 American heart association/american stroke association focused update of the 2013 guidelines for the early management of patients with acute ischemic stroke regarding endovascular treatment: A Guideline for Healthcare Professionals From the American Heart Association/American Stroke Association. Stroke. 2015; 46:3020-35.

11. Rai AT, Jhadhav Y, Domico J, Hobbs GR. Procedural predictors of outcome in patients undergoing endovascular therapy for acute ischemic stroke. Cardiovasc Intervent Radiol. 2012; 35:1332-9.

12. Bang OY, Saver JL, Kim SJ, Kim GM, Chung CS, Ovbiagele B, Lee KH, Liebeskind DS. Collateral flow predicts response to endovascular therapy for acute ischemic stroke. Stroke. 2011; 42:693-9.

13. Leng X, Fang H, Leung TW, Mao C, Xu Y, Miao Z, Liu L, Wong KS, Liebeskind DS. Impact of Collateral Status on Successful Revascularization in Endovascular Treatment: A Systematic Review and Meta-Analysis. Cerebrovasc Dis. 2016; 41:27-34.

14. Albers GW, Thijs VN, Wechsler L, Kemp S, Schlaug G, Skalabrin E, Bammer R, Kakuda W, Lansberg MG, Shuaib A, Coplin W, Hamilton S, Moseley M, et al. Magnetic resonance imaging profiles predict clinical response to early reperfusion: the diffusion and perfusion imaging evaluation for understanding stroke evolution (DEFUSE) study. Springer Plus. 2006; 60:508-17.

15. Davis SM, Donnan GA, Parsons MW, Levi C, Butcher KS, Peeters A, Barber PA, Bladin C, De Silva DA, Byrnes G, Chalk JB, Fink JN, Kimber TE, et al. Effects of alteplase beyond $3 \mathrm{~h}$ after stroke in the Echoplanar Imaging Thrombolytic Evaluation Trial (EPITHET): a placebocontrolled randomised trial. Lancet Neurol. 2008; 7:299-309.

16. Kim SJ, Son JP, Ryoo S, Lee MJ, Cha J, Kim KH, Kim GM, Chung CS, Lee KH, Jeon P, Bang OY. A novel magnetic resonance imaging approach to collateral flow imaging in ischemic stroke. Ann Neurol. 2014; 76:356-69. 
17. Uemura A, O’Uchi T, Kikuchi Y, Yashiro N, Ihara N, Shoji K. Prominent laterality of the posterior cerebral artery at three-dimensional time-of-flight MR angiography in M1-segment middle cerebral artery occlusion. AJNR Am J Neuroradiol. 2004; 25:88-91.

18. Ichijo M, Miki K, Ishibashi S, Tomita M, Kamata T, Fujigasaki H, Mizusawa H. Posterior cerebral artery laterality on magnetic resonance angiography predicts long-term functional outcome in middle cerebral artery occlusion. Stroke. 2013; 44:512-5.

19. Lima FO, Furie KL, Silva GS, Lev MH, Camargo EC, Singhal AB, Harris GJ, Halpern EF, Koroshetz WJ, Smith WS, Yoo AJ, Nogueira RG. The pattern of leptomeningeal collaterals on CT angiography is a strong predictor of long-term functional outcome in stroke patients with large vessel intracranial occlusion. Stroke. 2010; 41:2316-22.

20. Menon BK, Smith EE, Modi J, Patel SK, Bhatia R, Watson TW, Hill MD, Demchuk AM, Goyal M. Regional leptomeningeal score on CT angiography predicts clinical and imaging outcomes in patients with acute anterior circulation occlusions. AJNR Am J Neuroradiol. 2016; 37 : 4613-4620.

21. Seeta Ramaiah S, Churilov L, Mitchell P, Dowling R, Yan B. The impact of arterial collateralization on outcome after intra-arterial therapy for acute ischemic stroke. AJNR Am J Neuroradiol. 2014; 35:667-72.

22. Yoo AJ, Verduzco LA, Schaefer PW, Hirsch JA, Rabinov JD, Gonzalez RG. MRI-based selection for intraarterial stroke therapy: value of pretreatment diffusionweighted imaging lesion volume in selecting patients with acute stroke who will benefit from early recanalization. Stroke. 2009; 40:2046-54.

23. Khatri P, Abruzzo T, Yeatts SD, Nichols C, Broderick JP, Tomsick TA, IMS I and II Investigators. Good clinical outcome after ischemic stroke with successful revascularization is timedependent. Neurology. 2009; 73:1066-72.

24. Jauch EC, Saver JL, Adams HP Jr, Bruno A, Connors JJ, Demaerschalk BM, Khatri P, McMullan PW Jr, Qureshi AI, Rosenfield K, Scott PA, et al. Guidelines for the early management of patients with acute ischemic stroke: a guideline for healthcare professionals from the American Heart Association/American Stroke Association. Stroke. 2013; 44:870-947.

25. Hong KS, Ko SB, Yu KH, Jung C, Park SQ, Kim BM, Chang CH, Bae HJ, Heo JH, Oh CW, Lee BC, Kim BT, Kim BS, et al. Update of the Korean Clinical Practice Guidelines for Endovascular Recanalization Therapy in Patients with Acute Ischemic Stroke. J BOUN. 2016; 18:102-13.
26. Kim SJ, Ha YS, Ryoo S, Noh HJ, Ha SY, Bang OY, Kim GM, Chung CS, Lee KH. Sulcal effacement on fluid attenuation inversion recovery magnetic resonance imaging in hyperacute stroke: association with collateral flow and clinical outcomes. Stroke. 2012; 43:386-92.

27. Maas MB, Lev MH, Ay H, Singhal AB, Greer DM, Smith WS, Harris GJ, Halpern E, Kemmling A, Koroshetz WJ, Furie KL. Collateral vessels on CT angiography predict outcome in acute ischemic stroke. Stroke. 2009; 40:3001-5.

28. Tomsick T, Broderick J, Carrozella J, Khatri P, Hill M, Palesch Y, Khoury J, Interventional Management of Stroke II Investigators. Revascularization results in the Interventional Management of Stroke II trial. AJNR Am J Neuroradiol. 2008; 29:582-7.

29. Brozici M, van der Zwan A, Hillen B. Anatomy and functionality of leptomeningeal anastomoses: a review. Stroke. 2003; 34:2750-62.

30. Shuaib A, Butcher K, Mohammad AA, Saqqur M, Liebeskind DS. Collateral blood vessels in acute ischaemic stroke: a potential therapeutic target. Lancet Neurol. 2011; 10:909-21.

31. Miteff F, Levi CR, Bateman GA, Spratt N, McElduff P, Parsons MW. The independent predictive utility of computed tomography angiographic collateral status in acute ischaemic stroke. Brain. 2009; 132:2231-8.

32. Bang OY, Saver JL, Buck BH, Alger JR, Starkman S, Ovbiagele B, Kim D, Jahan R, Duckwiler GR, Yoon SR, Vinuela F, Liebeskind DS, UCLA Collateral Investigators. Impact of collateral flow on tissue fate in acute ischaemic stroke. J Neurol Neurosurg Psychiatry. 2008; 79:625-9.

33. Bang OY, Saver JL, Kim SJ, Kim GM, Chung CS, Ovbiagele B, Lee KH, Liebeskind DS, UCLA-Samsung Stroke Collaborators. Collateral flow averts hemorrhagic transformation after endovascular therapy for acute ischemic stroke. Stroke. 2011; 42:2235-9.

34. Fanou EM, Knight J, Aviv RI, Hojjat SP, Symons SP, Zhang L, Wintermark M. Effect of Collaterals on Clinical Presentation, Baseline Imaging, Complications, and Outcome in Acute Stroke. AJNR Am J Neuroradiol. 2015; 36:2285-91.

35. Son JP, Lee MJ, Kim SJ, Chung JW, Cha J, Kim GM, Chung CS, Lee KH, Bang OY. Impact of Slow Blood Filling via Collaterals on Infarct Growth: Comparison of Mismatch and Collateral Status. J Stroke. 2017; 19:88-96.

36. Tsushima Y, Endo K. Significance of hyperintense vessels on FLAIR MRI in acute stroke. Neurology. 2001; 56:1248-9.

37. Liebeskind DS. Location, location, location: angiography discerns early MR imaging vessel signs due to proximal arterial occlusion and distal collateral flow. AJNR Am J Neuroradiol. 2005; 26:2432-3. 